\title{
The Case of Organizational Innovation Capability and Health Information Technology Implementation Success: As You Sow, So You Reap?
}

\author{
Rangarajan Parthasarathy, University of Illinois at Urbana-Champaign, USA \\ Monica Garfield, Bentley University, USA \\ Anuradha Rangarajan, Indiana State University, USA \\ Justin L. Kern, University of Illinois at Urbana-Champaign, USA
}

\begin{abstract}
Organizational innovation capability is defined as the ability to continuously transform knowledge and ideas into new products, processes, and systems for the benefit of an organization and its stakeholders. This study examines the relationship between the innovation capability of healthcare organizations and their ability to successfully implement electronic medical records (EMR), a health information technology (HIT) innovation. Data was collected using a cross-sectional survey, and structural equation modeling (SEM) method was used to analyze the data. Results demonstrate that organizational product innovation capability positively affects EMR implementation success. A positive relationship also exists between organizational process innovation capability and EMR implementation success. This study is one of the first to empirically validate the relationship between healthcare organization's innovation capability and HIT innovation implementation success, in the context of EMRs. Implications of the study for the academic and industry practitioner are discussed.
\end{abstract}

\section{KEYWORDS}

Electronic Medical Records (EMR), Health Information Technology Implementations, Organizational Innovation, Socio-Technical Systems Theory, Tri-Core Model for Information System Innovation

\section{INTRODUCTION}

Organizational innovation capability has been considered an important ingredient for success. This is more relevant today than ever before, due to the intense competition in the healthcare and nonhealthcare industry (Calantone, Cavusgil \& Zhao, 2002; Damanpour, 1996, 1991, 1987; Damanpour \& Evan, 1984; Gonzalez-Zapatero et al., 2016; Mu et al., 2017; Najafi-Tavani et al., 2016). Innovation can be defined as the intentional introduction and application within a role, group, or organization, of ideas, processes, products, or procedures new to the relevant unit of adoption and designed to significantly benefit the individual the group or the wider society (West, 1990). Technological innovation refers to "the implementation of an idea for a new product, or a new service, or the introduction of new elements in an organization's production process or service operation" (Damanpour and Evan, 1984, 
p. 394). Innovation capability is "the ability to continuously transform knowledge and ideas into new products, processes and systems for the benefit of the firm and its stakeholders" with this higher order capability enabling the molding and management of multiple capabilities to successfully stimulate innovation (Lawson and Samson 2001, pp. 380, 384). Organizational innovation capability essentially involves the bringing to the market and/or successful implementation of a new product or service (Adler \& Shenbar, 1990). Scholars have described it as the ability to mobilize the knowledge of the employees and the organization from past innovation implementation experiences to create new knowledge, and use such new knowledge to implement a new product or service (Çakar \& Ertürk, 2010; Kogut \& Zander, 1992; Ranganathan \& Afnan, 2012). A firm with the capability to enhance its organization's learning and assimilate existing and new knowledge would also have the capability to successfully create and implement product and process innovations (Therin, 2003).

Research literature informs us about the important role of health information technology (HIT) innovations in improving healthcare quality and the cost of care (Bezboruah et al., 2014; Chaudhry et al., 2006; Cresswell \& Sheikh, 2013; Gewald \& Gewald, 2020; Gagnon et al., 2012; Li et al., 2013; Narattharaksa et al., 2016). In the realm of healthcare, electronic medical records (EMR) fit the profile of technology innovations (Crane \& Crane, 2006; Dansky et al., 2006; Dansky \& Dirani, 1998; Dansky et al., 1998; Holt et al., 2019; Krist, 2015; Lee et al., 2016; Lee, 2000; Pellizzoni et al., 2020; Perez et al., 2017). EMR implementation is an important aspect of HIT, perhaps the most important aspect, since it has the potential to directly impact cost reduction and quality improvement in healthcare delivery through: (i) lowering the processing times associated with enormous amounts of patient information within and between hospitals, (ii) enhancing the speed and quality of communications between patients and the healthcare providers, and between healthcare providers and other healthcare providers or specialists that need to be involved in patient care, and (iii) delivering evidence-based high-quality healthcare through collection and mining of patient information using computers (Hillestad et al., 2005; Jardim \& Martins, 2016; Sharma et al., 2016). HIT and EMR are eventually expected to contribute to the delivery of high-quality healthcare to all sections of society at a reasonable cost (Byrd \& Clayton, 2001; Ferlie \& Shortell, 2001; Jardim \& Martins, 2016; Sharma et al., 2016; Thakur et al., 2012; Trzeciak \& Rivers, 2003).

The healthcare industry has been characterized as complex, turbulent, fragmented, and tightly coupled (Shekelle et al., 2006; Greenhalgh et al., 2009). This is mirrored in research studies which have highlighted complexities inherent in the implementation of HIT innovations (Martikainen et al., 2020; Parks et al., 2019; Sittig \& Singh, 2015; Sligo et al., 2017; Stroetmann, 2014). EMR implementations around the world have been slow and fraught with problems (Cresswell et al., 2020b; Jawhari et al., 2016a; Raut et al., 2017; Reisman, 2017, Yi, 2018). It is known from research literature that $50 \%$ to 95\% of information systems (IS) projects fail to be implemented successfully, and $20 \%$ to $30 \%$ of EMR implementations fail within the first year (Palvia et al., 2015; Sumner, 2015). This situation persists in the United States too, despite the monetary incentives provided by the government (AdlerMilstein et al., 2015; Barrett, 2018; Kharrazi et al., 2018). In the United States, the healthcare system is very complex, in part due to the various types of healthcare-providing institutions and the many insurance establishments involved in providing healthcare, as well as due to the complex laws that cover healthcare schemes such as Medicare and Medicaid (Byrd \& Clayton, 2001; Ferlie \& Shortell, 2001; Thakur et al., 2012; Trzeciak \& Rivers, 2003). The ever-increasing healthcare costs and everchanging complex laws make delivering high-quality evidence-based healthcare at an affordable cost a perpetual challenge for healthcare providers in the United States (Byrd \& Clayton, 2001; Ferlie \& Shortell, 2001; Thakur et al., 2012; Trzeciak \& Rivers, 2003).

A deeper investigation into the reasons for EMR implementation challenges in past research studies has identified the causes to be largely organizational and social in nature and less to do with the technology itself, though there is some evidence in favor of the latter as well. These sociotechnical challenges include a perceived lack of information technology (IT) support, perceived lack of productivity and efficiency in transitioning to a paperless system, financial capabilities related 
to the total cost of EMR ownership, vendor selection related to integrating of EMR technology, and perceived loss of privacy and security of patient data (Chan et al., 2016; Palabindala et al., 2016; Zandieh et al., 2008). Physician's resistance to change and physician burnout has also been widely studied among HIT scholars (Barrett, 2018; Beglaryan et al., 2017; Colicchio et al., 2019; Zandieh et al., 2008). By contrast, EMR implementation costs are typically documented as upfront implementation costs and annual maintenance costs (Brooks \& Grotz, 2010; Hillestad et al., 2010; Kanga et al., 2016; Patil et al., 2008). It is evident from research literature that the planning for largescale HIT implementations such as EMR often does not account for the effort and costs involved in addressing the socio-technical challenges mentioned above. Perhaps due to the varied dimensions of difficulties associated with their successful implementation, the implementation of HIT innovations such as EMR's has lagged the implementation of non-healthcare innovations in industry (Black et al., 2011; Cresswell \& Sheikh, 2013). The relationship between the socio-technical perspective, impact of HIT innovations on healthcare quality and costs, complexities relating to HIT innovation implementations, and the lagging of the HIT innovation implementation scenario is a symbiotic one as described previously. Our research on the impact of organizational innovation capability on HIT implementation success is based on such symbiotic relationship.

\section{BACKGROUND AND THEORETICAL FRAMEWORK}

The two major areas of research literature providing the necessary theoretical foundation for this study are the organizational innovation capability literature, and the research literature in the two major areas of IS and HIT innovation implementation - the socio-technical systems (STS) theory (Trist et al., 1963), and the tri-core model of IS innovation (Swanson, 1994). Together they support the formation of the research hypotheses for this research study, and are discussed next.

\section{Organizational Innovation Capability}

That continual innovation is critical to organizational success is indisputable, especially in the extremely competitive industrial climate we live in today (Al-Hakim \& Hassan, 2016; Damanpour, 1996; Joshi et al., 2010; Kim \& Chung, 2017; Ries, 2011). Innovation has been studied from different perspectives in academic research. Organizational innovation capability requires finding a good balance between flexibility and control which are often in conflict with each other. While flexibility enables creativity and change vital for the exploration that stimulates innovation, control underscores discipline, long-term goals, core competencies and budgets (Khazanchi et al., 2007). Because even the most stable environments do change, which leads to organizations adopting innovations continually over time, organizational innovativeness is more accurately represented when multiple innovations over a period of time are considered (Damanpour, 1987, 1991, 1996). Christensen (1999) contended that in addition to his/her other duties and responsibilities, a manager must also manage innovation within the organization. Downs and Mohr (1976) questioned whether variability in the type of innovation has an influence on its adoption, or if different variables may have different explanatory roles depending on the innovation's context.

Organizational psychologists Klein and Knight (2005) have researched the organizational challenges that impede innovation implementation along with certain characteristics that need to work together to increase the likelihood of successful implementation. Such characteristics, which could also become stumbling blocks on the road to implementation, include i) unreliability of the innovation, ii) need for users to acquire new technical knowledge and skills, iii) disparity in organizational hierarchies making decisions and those implementing them, iv) disruption in pre-established organizational norms, v) up-front time and financial investments, and vi) organizational inertia to maintain status quo (Klein \& Knight, 2005). Obviously, most of these barriers are organizational issues rather than technical issues. Antecedents to effective implementation include an organizational climate for innovation implementation, and organizational learning orientation (Klein \& Knight, 2005). Learning conditions 
are individual characteristics of a single user, while learning is also a multi-step social process through which an organization acquires tacit knowledge from its external environment (MacVaugh \& Schiavone, 2010). In their expansive literature study on the limits of the diffusion of innovation across marketing, new product development and sociology domains, MacVaugh and Schiavone (2010) emphasized that innovation diffusion is affected by the technological, social, and learning conditions which operate in the contextual domain of the individual, community or market/industry.

Innovation could be the creation or adoption of a product or service, a new production process technology, a new structure or administrative system, or a new plan or program pertaining to organizational members (Çakar \& Ertürk, 2010; Damanpour \& Evan, 1984; Khazanchi et al., 2007; Zaltman et al., 1973). Innovation capability and organizational innovativeness are conceptualized from the perspective of the rate of adoption of innovations as well as an organization's inclination to change (Calantone, Cavusgil \& Zhao, 2002; Hurt et al., 1977). An organization's ability to innovate also depends on a supporting culture that encourages creativity, experimentation and risk taking (Jassawalla \& Sashittal, 2002). It could conceivably refer to how early an organization seeks to adopt a new product, process or service relative to other organizations (Damanpour, 1991; Hunt \& Morgan, 1996; Hurt et al., 1977; Hurt \& Teigen, 1977; Rogers \& Shoemaker, 1971).

\section{Innovations in the Information Systems and Health Information Technology Context}

In the context of information systems (IS), innovation has been described as any new way of developing, implementing, and maintaining information systems in an organizational context (Avgerou, 2003). Prior work in IS innovation research has forwarded the resource-based view, which interprets the ability to leverage IS in new ways as being a core competence of an organization as well as a source of sustainable competitive advantage (Feeny and Willcocks, 1998). For successful adoption of IS innovations, institutional processes need to be engaged early (Swanson and Ramiller, 1997). To leverage the value of IS, organizations need to recognize and develop competencies whose elements are distributed throughout the organization, and are not solely resident in the IS function (Peppard et al., 2000). Over the last two decades, numerous researchers have forwarded frameworks for IS innovation from a socio-technical perspective (Avegerou, 2003; Baxter \& Sommerville, 2011; Gregor \& Hevner, 2015; Lee et al., 2008; Lin et al., 2016; Luna-Reyes et al., 2005; Palvia et al., 2001; Winter et al., 2014). However, the adoption of such frameworks in HIT research has been limited.

The healthcare sector is considered to have a unique, complex, dynamic context as stated previously, which differs significantly from that of other industries where IS innovations have been applied (Andargoli et al., 2017; Savory \& Fortune, 2015; Westbrook et al., 2004). Therefore, taking a contextual sensitive approach towards HIT research is critical (Chiasson \& Davidson, 2004). Unfortunately, the study of organizational dimensions involved in HIT innovation implementation success is not a clearly defined area of interest (Cresswell \& Sheikh, 2013; Cresswell et al., 2020). The reasons for HIT adoption and implementation failures in healthcare organizations are primarily organizational rather than technical (Kaplan \& Harris-Salamone, 2009). This statement is consistent with the findings in research literature of a body of scholars involved in HIT research who have cited the need to incorporate perspectives other than the technology itself when studying the implementation of HIT innovations. Some researchers have also utilized Roger's diffusion of innovation (DOI) model to explain innovation diffusion within healthcare organizations and within a HIT implementation success context (Ash 1997; Barrett \& Stephens, 2017; Cain \& Mittman, 2002; Dolezel \& Mcleod, 2019; Emani et al., 2012; Emani et al., 2018; Gagnon et al, 2014; Gosling et al;, 2003; Greenhalgh et al., 2004; Lin et al., 2016; Neumeier, 2013; Putzer \& Park, 2012). However, its focus is on the adoption of the diffused innovations by individuals within organizations and (Lundblad, 2003) where less attention is paid to different structural and social processes within the whole system that make up the innovation's journey (Cranfield et al., 2015).

With regards to the implementations of HIT innovations such as EMR, there is no one particular over-arching conceptual framework available from academic literature (Creswell \& Sheikh, 2013; 
Cresswell et al., 2020). Identifying this as a systemic gap, some healthcare scholars have attempted to identify frameworks applicable in a HIT context (Chaudoir et al., 2013; Cresswell et al., 2020; Sittig $\&$ Singh, 2015). Few studies have examined the association between organizational innovation and HIT implementation (Basole \& Rouse, 2009; Leidner et al., 2010; Acar \& Acar, 2012). Scholars have reviewed the impact of broader organizational and social factors on EMR implementation success (Chan et al., 2016; Cresswell et al., 2013; Kilsdonk et al., 2017; Sittig \& Singh, 2015; Tutty et al., 2019). Others have studied the impact of corporate culture and managerial absorptive capacity on HIT implementations (do Carmo Caccia-Bava et al., 2006). However, there are no research studies that have specifically investigated the association between organizational innovation capability and EMR implementation success, particularly by way of examining the application of STS and tri-core model on EMR innovation implementations in the healthcare domain. In the next section, we examine and discuss the applicability of the aforementioned theories in the context of this research study.

\section{The Socio-Technical Systems Theory}

The socio-technical systems (STS) theory, originally developed at the Tavistock Institute of Human Relations in London, has been widely adopted as a framework for studying successful organizational change driven by technology adoption and incorporation of technological advancement within organizations (Applebaum, 1997, Damanpour et al., 1989). The theory posits that an organization is a combination of its social and technical parts and is open to its environment (Trist et al., 1963). For balance to be maintained between the two systems, changes introduced in the two systems should be congruous. While a one-to-one correspondence between administrative and technical innovations is not advocated or expected, a balance in the rate of adoption of the two innovation types is necessary to ensure equilibrium between the social structure and the technical system for effective operation of the entire organization (Trist, 1981). In other words, organizational innovation is a necessary precondition for technological innovation to be fully implemented and exploited (Azar \& Ciabuschi, 2017; Damanpour, et al., 1989; Lam, 2005). Organizational innovations lead to enhanced intraorganizational coordination and cooperation, which, in turn create the appropriate environment for adoption and utilization of technological innovations (Damanpour \& Evan, 1984).

Past research studies have utilized the STS theory to understand the relationship between organizational innovation and technology innovation implementation (Azar \& Ciabuschi, 2017; Damanpour \& Evan, 1984; Hamel, 2006; Baxter \& Hester, 2014; Kwahk and Ahn, 2010; Liu et al., 2006; Sackey et al., 2015; Westbrook et al., 2007).

\section{Tri-Core Model of IS Innovation}

Swanson (1994) proposed the tri-core model to address certain aspects of IS innovations such as: how IS innovations differ from other organizational innovations, are there different forms of IS innovations, and how IS innovations diffuse among organizations and with what consequences. To answer these questions, Swanson (1994) identified a typology of IS innovations realizing that IS innovations may involve a new IS product of service, a new IS work technology, or a new IS administrative arrangement. Type I innovations focus on IS administration, and can incorporate IS administrative tasks or technical IS tasks. Type II innovations apply IS products and services to the administrative core of the organization's business, with important ramifications to the internal IS work processes. Type III innovations integrate IS products and services with core business technology and typically impacts general business administration. These types of innovations are typically strategic and offer competitive advantage through product or service differentiation. Interaction among the innovation types is posited leading to diffusion and adoption in an organizational context. Scholars have utilized the tri-core model to better understand the role IS innovations play in administrative, technical, and operational effectiveness (Costello \& Donnellan, 2007; Grover et al., 1997; Lee \& Fiedler, 2011; Lyytinen \& Rose, 2003; Liu et al., 2014). 
Figure 1. Theoretical context of research model

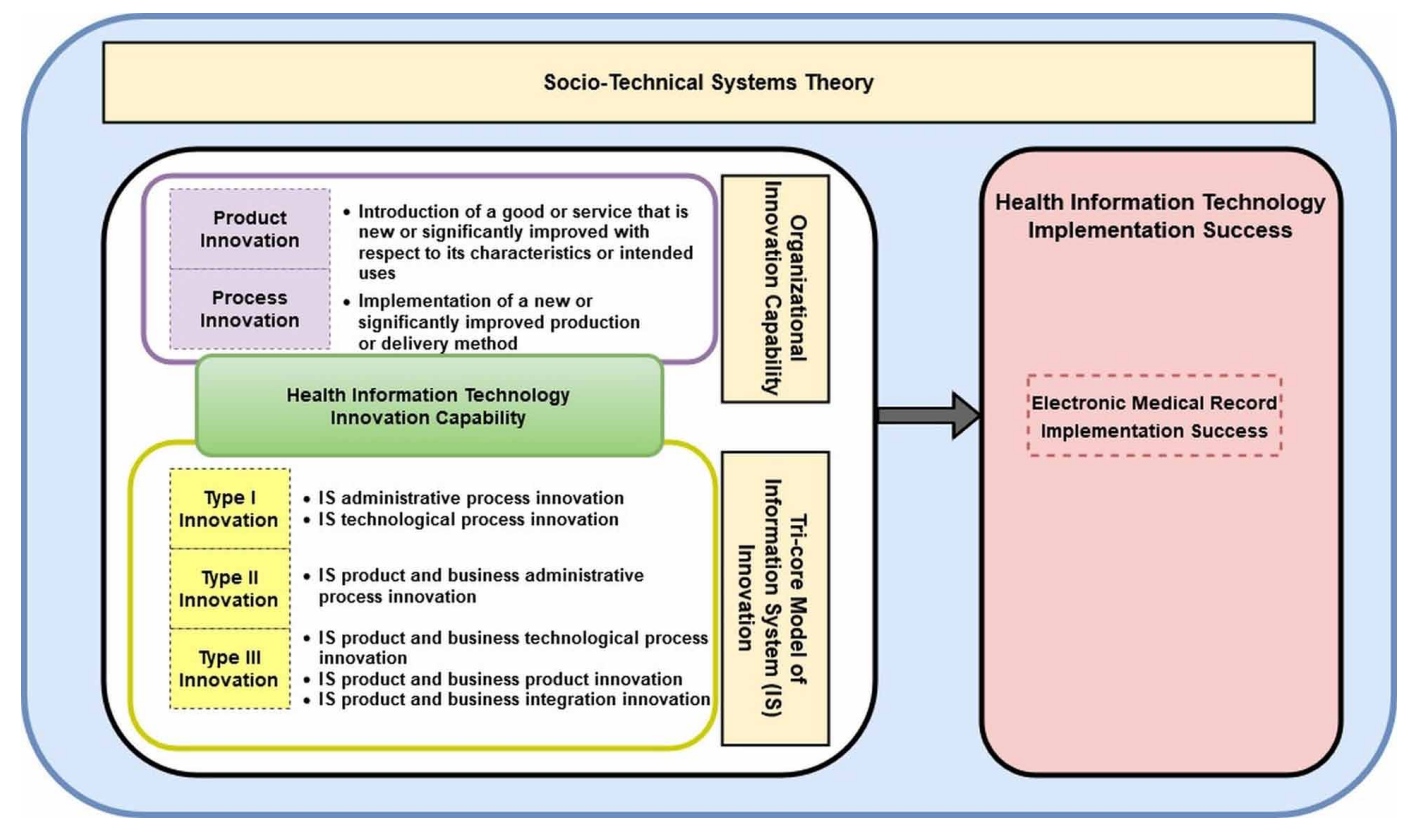

In the context of the tri-core framework, Swanson (1994) emphasized that IS innovations may involve a new IS product or service, a new IS work technology, or a new IS administrative arrangement. EMRs encompass Type I innovations such as the core EMR technology, including the supporting database storage technology and supporting hardware infrastructure (Azaria et al., 2016). From a Type II innovation perspective, use of EMR has been associated with healthcare workflow related efficiency gains (Vishwanath et al., 2010). When implemented successfully, EMRs have been reported to enhance competitive advantage for healthcare providers by enabling complementary products or services thereby supporting Type III innovations (Porter, 2009). Therefore, it can be stated that the tri-core model aptly provides an IS innovation lens to examine the success and failure of HIT implementations (e.g., EMR) in an organizational context. Figure 1 depicts the overall theoretical context for this study.

\section{HYPOTHESES}

Innovation scholars have cited that product and process innovation within an organization influence the innovation capability of the organization, which in-turn influences the innovation performance of the organization (Damanpour, 1991; Hurley \& Hult, 1998; Mir et al., 2016; Therin, 2003). Organizational innovation is a necessary precondition for technological innovation to be fully implemented and exploited (Azar \& Ciabuschi, 2017; Damanpour, et al., 1989; Lam, 2005). Such reasoning is consistent with the essence of the STS theory. Moreover, scholars have also viewed EMR as both a process innovation (Carayon et al., 2015; Laird-Maddox et al., 2014; Lorenzi et al., 2004), and a product innovation (Bloomfield et al., 2017; Guo et al., 2017; Katzan et al., 2011). To holistically assess implementation success, we argue that a comprehensive view that assimilates both the organizational process and product aspects of HIT innovation is required. This can help answer the following important research questions: why do some technologically sound HIT innovations fail, can the innovation capability of a healthcare organization play a role in successful HIT implementations, what is the value attained from the time and monetary investments of healthcare organizations in 


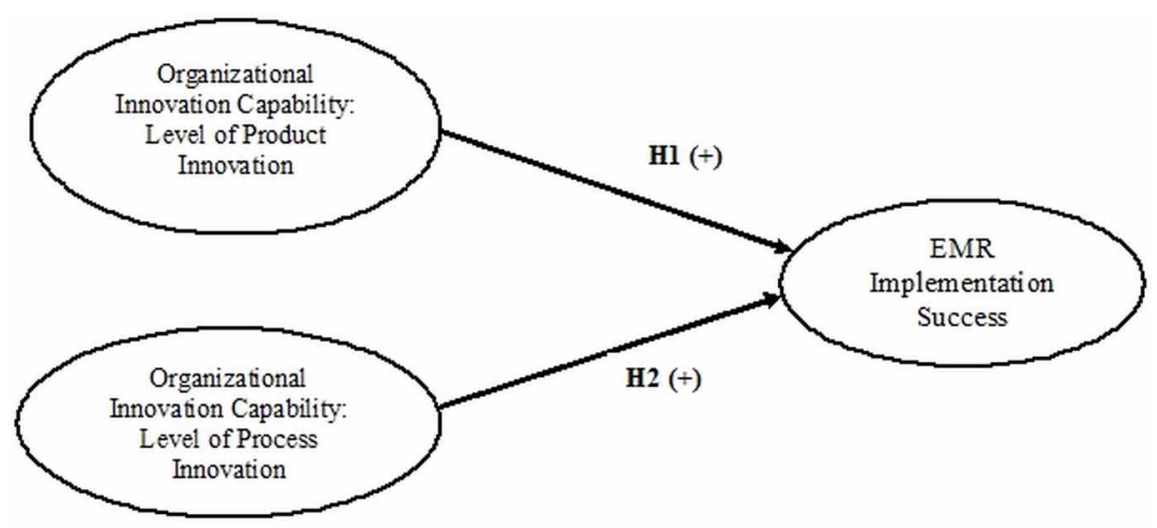

improving their organizational innovation capability. Finding the answers to these questions will help in better understanding the role played by organizational innovation capability in the implementation success of HIT innovations such as EMR.

The United Nations Educational, Scientific and Cultural Organization (UNESCO) (2005) defines product innovation as the introduction of a good or service, that is new or significantly improved with respect to its characteristics or intended uses. Such significant improvements include improvements in technical specifications, components and materials, incorporated software, and friendliness or other functional characteristics. Process innovation is defined as the implementation of a new or significantly improved production or delivery method. This includes significant improvements in techniques, equipment and/or software. Though the customer does not usually pay directly for the process, the process is required in order to deliver a product or service that offers value and satisfaction to the customer. The process should also enable the management of the relationship with the various stakeholders (UNESCO, 2005).

Therefore, we posit that an organization with a high level of product and process innovation based on high innovation capability and past product implementation successes would have the experience and know-how to successfully implement a technology innovation such as an EMR system. Based on the above discussion, the following hypotheses are presented and depicted in figure 2 .

Hypothesis 1 (H1): The level of process innovation existing in the organization will positively correlate with EMR implementation success.

Hypothesis 2 (H2): The level of product innovation existing in the organization will positively correlate with EMR implementation success.

\section{Implementation Success}

Delone and Mclean (1992) suggested that when the use of a specific system/technology is geared towards a specific purpose, user satisfaction may be an appropriate measure of success. User satisfaction has the advantage of having a high degree of face validity since it is hard to deny the success of a system which its users say they like (Delone \& Mclean, 1992). EMR implementation is concerned with medical records in electronic format, and hence involves a specific and unique system/ technology. In the United States, with few exceptions, EMR implementation and use is required as opposed to being voluntary or non-mandatory. Keeping this in mind, user satisfaction has been adopted as one of the constructs in this study to measure the dependent variable EMR implementation success. 
Implementing a new technology innovation such as EMR involves considerable expense of time and money, and so it is conceivable that organizations implementing EMR will want to assess the success of the implementation in terms of the value offered by the EMR system through its functionality, versus the cost to implement. Other IS implementations such as enterprise resource planning (ERP) implementations have regarded system functionality as one of the main factors for implementation success (Hong \& Kim, 2002; Laughlin, 1999; Rolland \& Prakash, 2001). EMR and ERP systems have a lot in common, such as both being relatively new technologies in their respective application areas, both having generic software modules that need to be customized in order to successfully implement the system to satisfy end users, and both being cost and labor intensive IS technologies. System functionality has therefore been utilized as an implementation success measure.

\section{METHOD}

\section{Sample}

It should be noted that EMR implementations in the United States typically include modules which assist in an array of healthcare functions. While this is not an exhaustive list, some functionality provided by EMRs include: i) managing emergency room visits, ii) performing ambulatory functions such as documenting visits, placing orders, sending communications to patients, iii) an in-patient version of the same that includes support for clinical notes, orders, medication administration, patient monitoring, discharge orders, iv) features that support providing specialized long-term care for ailments such as oncology treatments, v) laboratory system integration, vi) enabling patient access of EMR data through patient-portals, vii) supporting multiple technical activities such as data warehousing, data reporting and analytics, data integration bridges, viii) aiding in healthcare provider's revenue cycle activities, and ix) tools and utilities for managing the system utilized by analysts, project managers, resource managers and healthcare executives ("About Cerner", 2020; "Epic Software \& Services", 2020; Newman, 2018). EMR systems in the United States are used by a wide variety of health professionals and healthcare industry employees including physicians, nurses, hospital administrators, project managers, and information technology professionals in the healthcare field, and therefore there cannot be a better set of respondents for a study such as this than these very professionals who use EMR day-in and day-out. In consideration of this, the respondent profile for this study consisted of health professionals (including physicians, nurses, hospital administrators, project managers), information technology professionals (IT consultants, project managers), and managers in the United States healthcare industry involved with the implementation, maintenance, and/or use of EMR for a minimum period of one year during the five years prior to taking the survey. Data was collected by distributing paper copies of the questionnaire, handing out postcards with the survey link at the leading healthcare conference of the Healthcare Information and Management Systems Society (HIMSS) conference, and posting the web link to the survey in the newsletter of HIMSS and in the intranet of healthcare organizations such as the Illinois Hospital Association.

\section{Measures}

The survey comprised of a demographic section followed by validated instruments adapted to measure organizational product and process innovation and EMR implementation success. The authors adapted a scale previously validated by Ju et al. (2006), to measure organizational product and process innovation. EMR implementation success was comprised of two constructs - user satisfaction (Seddon and Yip, 1992), and system functionality success (Do Carmo-Caccia-Bava et al., 2006). For each item a seven-point Likert scale was used, ranging from "strongly disagree" to "strongly agree". A list of all the constructs and measurement items is provided in Table IV. 
Table 1. Respondent organization type

\begin{tabular}{|l|l|}
\hline \multicolumn{1}{|c|}{ Organization Type } & \multicolumn{1}{c|}{ Distribution of Respondents } \\
\hline Single Hospital/Multi-Hospital System/Integrated Delivery System & $83.5 \%$ \\
\hline Public Health organization & $42.1 \%$ \\
\hline Community Health Center & $30.0 \%$ \\
\hline Long-term Care Facility & $21.9 \%$ \\
\hline Ambulatory Clinic (Hospital Owner) & $15.2 \%$ \\
\hline Government Institution (Federal/State/Local Government) & $14.6 \%$ \\
\hline Ancillary Clinical Services Provider & $12.1 \%$ \\
\hline Payer/Insurer Managed Care Organization & $9.6 \%$ \\
\hline Academic Medical Center (affiliated with a college or university) & $6.3 \%$ \\
\hline Physician's Office & $4.4 \%$ \\
\hline Ambulatory Clinic (independent) & $1.3 \%$ \\
\hline Other (please specify) & $0.8 \%$ \\
\hline
\end{tabular}

\section{Data Analysis Strategy}

Structural Equation Modeling (SEM) was used for the data analysis due to the presence of latent variables in the research model (Hoyle, 1995). Reliability of a measurement instrument is the extent to which it yields consistent results when the characteristic being measured hasn't changed (Leedy \& Ormrod, 2015). The most often used measure for internal consistency reliability is Cronbach's Alpha, with Cronbach's Alpha values higher than 0.70 speaking to good instrument reliability (Streiner, 2003; Nunnally, 1967; Cronbach, 1951). Multicollinearity was tested using the variance inflations (VIF). VIF value exceeding 10 suggests severe multicollinearity (Freund et al., 2006; Hair et al., 1995; Kutner et al., 2005; Mason et al., 1989). VIF thresholds of 5 are common in research literature (De Jongh et al., 2015). In addition to this, the tolerance estimates for each variable must be greater than 0.20 to verify the absence of multicollinearity (Darlington, 1990).

\section{RESULTS}

\section{Descriptive Statistics}

A total of 476 usable survey responses were obtained. Approximately $63 \%$ of respondents had between one and three years of experience with EMR implementation, use, or maintenance, and about 37\% had between three and five years. With respect to the organization type in which the respondent EMR experience took place, about $84 \%$ of respondents stated that their EMR experience was in a single hospital/multi-hospital system/integrated delivery system. Multiple responses were allowed for this question due to the possibility that the respondents' organizations fell into more than one category. Table 1 summarizes respondent's organization type.

With regards to the primary occupational area of the respondents, the distribution of responses is shown in Table 2. A large proportion of respondents (43\%) had technical (IT/IS consultant, programmer, systems developer) as their primary occupational area. The distribution of the professional societies that the respondents' belonged to is shown in Table 3. Multiple responses were allowed for this question since it is conceivable that the respondents belonged to more than one professional society. From the responses, the highest percentage of respondents (92\%) belonged to the Health Information and 
Table 2. Primary occupational area

\begin{tabular}{|l|l|}
\hline \multicolumn{1}{|c|}{ Occupational Area } & \multicolumn{1}{|c|}{ Distribution of Respondents } \\
\hline Technical (examples: IT/IS consultant, programmer, systems developer) & $42.9 \%$ \\
\hline $\begin{array}{l}\text { Health Professional (examples: doctor, nurse, physician's assistant, } \\
\text { pharmacist, physical therapist) }\end{array}$ & $31.3 \%$ \\
\hline Project Management (examples: project manager, project assistant) & $16.0 \%$ \\
\hline Business (examples: business manager, operations manager) & $9.2 \%$ \\
\hline Other (please specify) & $0.6 \%$ \\
\hline Social (examples: social worker, volunteer) & $0 \%$ \\
\hline
\end{tabular}

Management Systems Society (HIMSS), followed by the American Health Information Management Association (AHIMA) (45\%) and the Project Management Institute (PMI) (24\%).

While $26 \%$ of the organizations the respondents belonged to had 3,001 to 6,000 full time direct employees, $21 \%$ of the organizations had 1,001 to 3,000 full time direct employees. $9 \%$ of the organizations had as high as 6001 to 10,000 direct employees, while $9 \%$ of the organizations had as low as 101 to 500 direct employees. A majority of the respondents were associated with relatively larger organizations such as hospitals (84\%), public health organizations $(42 \%)$, and community health centers $(30 \%)$ rather than with relatively smaller organizations such as privately owned physician's offices (4\%) and ancillary clinical services providers (12\%).

With respect to annual revenue, about $27 \%$ of the organizations had a total annual revenue of greater than $\$ 3$ Million but less than \$5 Million, and 21\% of the organizations had greater than $\$ 5$ Million but less than $\$ 10$ Million. Approximately $17 \%$ of the organizations had a total annual revenue between $\$ 1$ Million and \$3 Million, and between \$0.5 and \$1 Million. Only 3\% of the organizations had a total annual revenue exceeding \$1 Billion, while 5\% of the organizations had a total annual revenue of $\$ 0.5$ Million or less. Assuming that annual revenues exceeding $\$ 3$ Million could be considered to be substantial, $56 \%$ of the organizations the respondents were affiliated with had substantial annual revenues.

Table 4 shows the items, reliability, and the variance extracted. The criterion of Fornell and Larcker (1981) has been commonly used to assess the degree of shared variance between the latent variables of the model. According to this criterion, the convergent validity of the measurement model can be assessed by the average variance extracted (AVE). AVE measures the level of variance captured by a construct versus the level due to measurement error, with values that are 0.7 and above being considered very good and a value of 0.5 being considered to be acceptable. The Cronbach's Alpha and AVE values for all constructs in this study was greater than 0.7 as shown in Table 4 . For the data

Table 3. Membership in professional societies

\begin{tabular}{|l|l|}
\hline \multicolumn{1}{|c|}{ Professional Society } & \multicolumn{1}{c|}{ Distribution of Respondents } \\
\hline Health Information and Management Systems Society (HIMSS) & $92.3 \%$ \\
\hline American Health Information Management Association (AHIMA) & $45.0 \%$ \\
\hline Project Management Institute (PMI) & $23.9 \%$ \\
\hline American Society for Quality (ASQ) & $12.5 \%$ \\
\hline Other (please specify) & $4.0 \%$ \\
\hline American Medical Association (AMA) & $1.3 \%$ \\
\hline
\end{tabular}


Table 4. Items, reliability, and variance extracted

\begin{tabular}{|c|c|}
\hline Construct and Items & Loadings \\
\hline \multicolumn{2}{|l|}{ Product Innovation (adapted from Ju et al., 2006) Cronbach's Alpha = .930; AVE $=.84$} \\
\hline The degree of product innovation in the organization is high. & 0.948 \\
\hline The degree of product innovation relative to the competitors is high. & 0.871 \\
\hline The potential applications of the product innovation in the organization are high. & 0.907 \\
\hline \multicolumn{2}{|l|}{ Process Innovation (adapted from Ju et al., 2006) Cronbach's Alpha = .940; AVE = .77 } \\
\hline The degree of process innovation in the organization is high. & 0.835 \\
\hline The degree of process innovation relative to the competitors is high. & 0.515 \\
\hline The potential applications of the process innovation in the organization are high. & 1.00 \\
\hline \multicolumn{2}{|c|}{$\begin{array}{l}\text { EMR Implementation Success - System Functionality Success (adapted from Do Carmo-Caccia-Bava et al., 2006) } \\
\text { Cronbach's Alpha }=\mathbf{. 7 2 0} ; \text { AVE }=\mathbf{. 7 0}\end{array}$} \\
\hline EMR provides or will provide good payback for cost. & 0.758 \\
\hline EMR is reliable and problem free. & 0.755 \\
\hline EMR facilitates an improved turnaround or response time. & 0.765 \\
\hline EMR creates a competitive advantage. & 0.750 \\
\hline EMR increases employee satisfaction overall. & 0.767 \\
\hline EMR reduces effort or costs. & 0.790 \\
\hline \multicolumn{2}{|l|}{$\begin{array}{l}\text { EMR Implementation Success - User Satisfaction (adapted from Seddon and Yip, 1992) } \\
\text { Cronbach's Alpha }=\mathbf{. 8 9 0} \text {; AVE }=\mathbf{. 7 0}\end{array}$} \\
\hline How adequately do you feel the EMR system meets information processing needs? & 0.855 \\
\hline How efficient do you feel EMR is? & 0.863 \\
\hline How effective do you feel EMR is? & 0.883 \\
\hline Construct and Items & Loadings \\
\hline Overall, how satisfied are you with EMR? & 0.911 \\
\hline
\end{tabular}

set under consideration, VIF values obtained were under 5 and the tolerance ratio was greater than 0.20 , thereby demonstrating the lack of multicollinearity.

\section{Hypotheses Testing}

A series of confirmatory factor analyses (CFA) were performed using the Lavaan package in R before testing the model for structural relations. Due to non-normality of the indicators, the Huber-White robust estimator (Huber, 1967; White, 1982) was used to estimate model parameters and standard errors. First, a one-factor model was fit with all indicators loading on a single general factor. This model fit very poorly, TLI $=.78, \mathrm{CFI}=.81, \mathrm{RMSEA}=.17$. This showed that the simplest structure (i.e., a model with just one factor) was not tenable. Next, a two-factor measurement model was fit by combining the product innovation and process innovation into a single "innovation" factor, and the user satisfaction and system functionality items into a single "implementation success" factor. While improving on fit compared to the one-factor model, the two-factor model still did not fit adequately, $\mathrm{TLI}=.87, \mathrm{CFI}=.89, \mathrm{RMSEA}=.13$. The next model split the innovation factor into its two constituent parts-namely, product innovation and process innovation — and fit the resulting three-factor model. This model significantly improved upon the two-factor model, while also fitting quite well, TLI $=.96$, $\mathrm{CFI}=.97, \mathrm{RMSEA}=.07$. Finally, the three-factor model was compared to the four-factor model. By 


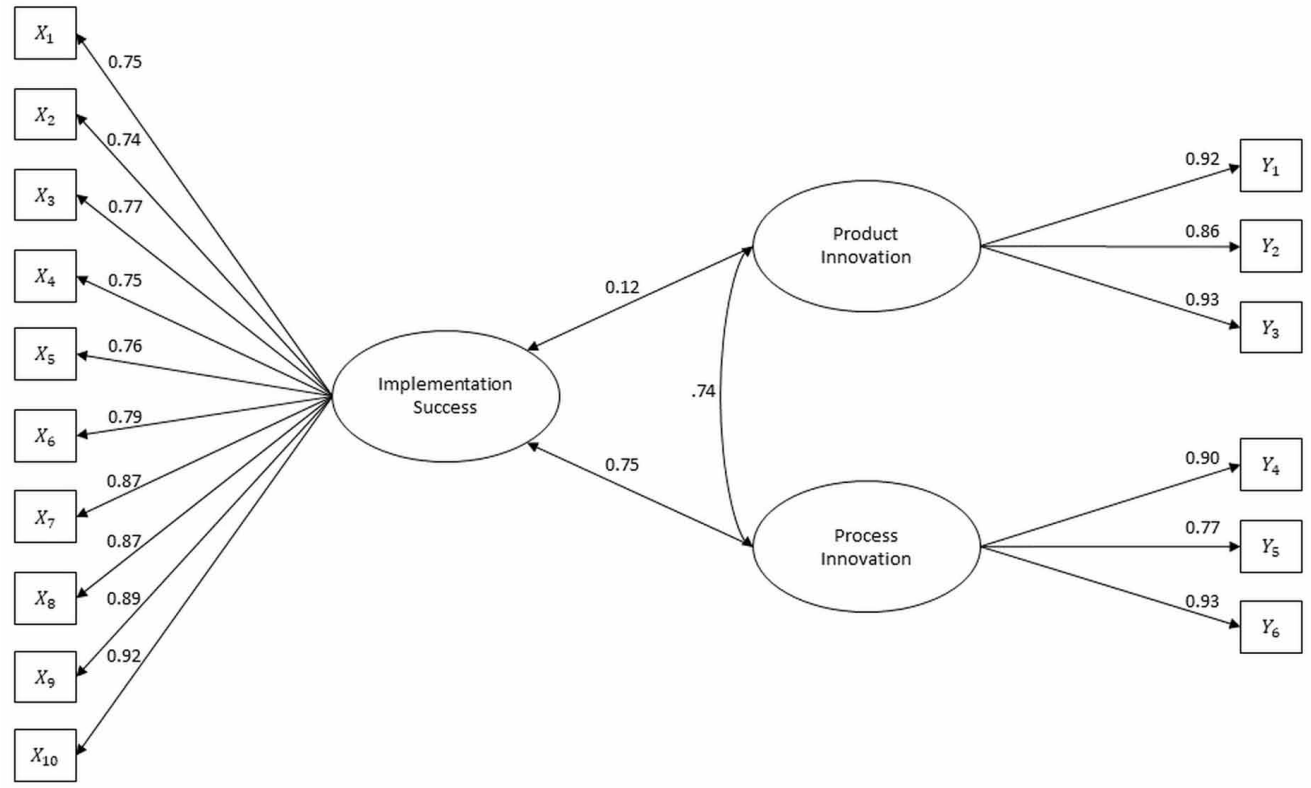

Table 5. Hypotheses results

\begin{tabular}{|l|l|}
\hline \multicolumn{1}{|c|}{ Hypotheses } & Result \\
\hline $\begin{array}{l}\text { H1: The level of process innovation existing in the } \\
\text { organization will positively correlate with EMR } \\
\text { implementation success. }\end{array}$ & Supported \\
\hline $\begin{array}{l}\text { H2: The level of product innovation existing in the } \\
\text { organization will positively correlate with EMR } \\
\text { implementation success }\end{array}$ & Supported \\
\hline
\end{tabular}

further looking at information criteria, the three-factor model was preferred with AIC and BIC both lower for the three-factor model (three-factor: $\mathrm{AIC}=14364.51, \mathrm{BIC}=14509.93$; four-factor: $\mathrm{AIC}=$ 14365.54, BIC = 14523.42). Here, we found that the four-factor model did not fit significantly better than the three-factor model. Subsequent analyses used the three-factor measurement. The loadings of the questions (items) on their respective constructs were between 0.74 and 0.92 with most being $>0.8$, indicating strong relationships (all were statistically significant $\mathrm{p}<0.01$ ).

An SEM model was fit regressing implementation success onto product innovation and process innovation utilizing the three-factor model. It was found that the model fit well, TLI $=.96, \mathrm{CFI}=.97$, $\mathrm{RMSEA}=.07, \chi^{2}(101)=274.80, p<.001$. Figure 3 shows the structural model. Results showed that process innovation $\left(\beta^{\wedge}{ }_{\text {Proc }}=0.75, p<0.001\right)$ and product innovation $\left(\beta^{\wedge}{ }_{\text {Prod }}=0.12, p=0.02\right)$ both significantly predicted implementation success. All factor loadings shown as standardized parameter estimates Figure 3 were significant. Results regrading support of hypotheses is summarized in Table 5. 


\section{DISCUSSION}

This section discusses the findings along with implications for both, the healthcare practitioner and researcher. From the practitioner's standpoint, this study has surfaced a vital finding. It is a widely accepted fact that unlike in other industries, successful implementation and adoption of IS systems in the healthcare industry requires acceptance from one major stakeholder group, namely the physicians. As physicians are the significant user-group supporting patient care, their intention to adopt EMR determines the overall success of its implementation (Dutta \& Hwang, 2020; Gewald $\&$ Gewald, 2020). Previous studies have revealed that physicians would not be interested in using a system that interferes with their workflow and modifies the way in which they care for their patients (Dutta \& Hwang, 2020). Physician's resistance to EMR systems has often been linked to factors such as reduced productivity, (perception of a) lack of usefulness, (inability of the EMR to easily accommodate) workflow changes, lack of interoperability, increased stress (resulting from EMR use), and lack of training and support acting as barriers (Hamamura et al., 2017; Jawhari et al., 2016b; Kruse et al., 2015; Or et al., 2018; Raglan et al., 2014; Reardon, 2009; Wager, 2008; Wallace et al., 2010). Per research literature, these are the very challenges that innovation-savvy organizations have overcome in order to successfully adopt other innovations (Dougherty \& Hardy, 1996; Hackler et al., 2007; Waarts et al., 2002). Mature organizations are known to: i) make resources available for newer products/processes, ii) provide collaborative structures and processes to solve problems creatively and connect innovations with existing businesses and, iii) incorporate innovation as a meaningful component of the organization's strategy (Dougherty \& Hardy, 1996). Therefore, healthcare industry leaders would be well-advised to follow these best-practices. Planning and budgeting to foster an environment conducive to organizational product and process innovation will pay itself forward by establishing collaborative structures and paving the way for HIT/EMR (and other innovation) implementation success.

According to Applebaum (1997), adopting an STS perspective can assist organizational executives with developing intervention strategies from the environment, structure, leadership procedures, people, and technology standpoints. Westbrook et al. (2007) stated that the introduction of HIT is prone to be at best indefinite and contradictory, and at worst, impossible to resolve satisfactorily making it a wicked problem to solve. The findings of this study should provide a direct and straightforward message to the managers and executives of healthcare organizations to focus on improving on the ability of their organizations to continuously innovate, both, in terms of product innovations and in terms of process innovations. To this end, they should plan and budget with a view to procuring the human resources and other resources which would allow their organizations to continuously innovate and build their innovation capability. This investment will, no doubt, pay itself forward in a multifold manner while proving time and again the complementary and symbiotic nature of these forces.

The results of the statistical analyses also provide valuable insights for researchers. This study has empirically validated that the product and process innovation capability of healthcare organizations is a significant antecedent to EMR implementation success. This is one of the first studies in HIT research literature to establish such a direct association. This association is of value because HIT scholars have emphasized that while technological functionalities are crucial in getting an initiative off the ground, system design needs to consider the accompanying social and organizational transformations which are invariably required to ensure that technologies deliver the desired value for a variety of stakeholders (Cresswell et al., 2020). Simply automating current paper-based manual processes by implementing EMRs would be an exercise in futility (Porter, 2009). This study extends the research finding from other domains that organizational innovation is a necessary precondition for technological innovation to be fully implemented and exploited to the healthcare domain, and thereby provides guidance to the industry practitioner with respect to creating an appropriate environment for successful implementation and adoption of technological innovations (Azar and Ciabuschi, 2017; Damanpour \& Evan, 1984; Damanpour et al., 1989). 
Disruptive technological innovations in healthcare offer a unique opportunity to understand and evaluate the changing inter-relationships between technology and human/organizational factors (Cressewell et al., 2012). Challenges to successful EMR implementations include the lack of robust organizational processes and structure, which acts as a significant barrier (Adler-Milstein, 2017; Cresswell et al., 2020; Lorenzi et al., 2008). According to Cresswell and Sheikh (2013), it is important to pay attention to the reciprocal relationships of technical, social, and organizational aspects at different stages of HIT implementation. Research literature states that the exact nature of the relationship among these dimensions is less clear, thereby highlighting the paucity of adequate research in this area. We believe that this study has contributed to research literature by identifying an important finding pertaining to inter-relationships between technology and human/organizational factors, by way of empirically identifying organizational innovation capability as a significant predictor for EMR implementation success.

A growing body of healthcare literature has identified the need to examine HIT implementations from a socio-technical perspective (Ash et al., 2012; Castro et al., 2016; Craig \& Kodate, 2018; Cresswell et al., 2012; Cresswell et al., 2020; Cresswell \& Sheikh, 2014; Hameed et al., 2012; Hsiao et al., 2011; Larisch et al., 2016; Sittig \& Singh, 2015; Singh \& Sittig, 2020). The nature of the healthcare field necessitates the study of processes associated with introduction of a new technology in social and organizational settings especially because a number of technological functionalities are often incorporated across varied implementation contexts (Cressewell et al., 2012). For example, Westbrook et al. (2007) characterized the delivery of safe and sustainable HIT systems for the future as a wicked problem due to its ill-defined and ambiguous nature which is associated with strong moral, political and professional issues. This study leveraged two socio-technical theories (STS and tri-core model) as a foundation to explore the impact of (healthcare) organizational process and product innovation capability on EMR implementation success. It has therefore examined HIT (EMR) implementations from a socio-technical perspective, and thereby made a contribution to research literature.

\section{LIMITATIONS}

As with any research study, this study too has some limitations. The first limitation relates to the data collection. The survey respondents (who met the required respondent profile) were drawn from those with memberships in professional associations such as the Healthcare Information and Management Systems Society (HIMSS), the American Healthcare Information Management Association (AHIMA), and the American Society for Quality (ASQ). The demographic profile of the respondents shows that a majority of the respondents were affiliated with single hospital/multi-hospital integrated delivery systems. Such organizations are likely to be relatively bigger in size with substantial annual revenues and a large employee headcount. There is the possibility that data collected from a different demographic may have yielded different results.

Secondly, this study was conducted in the United States and therefore it is reasonable to assume that the respondents were residents of the United States. If this study were to be conducted in other countries/cultures with the respondents being residents of those countries/cultures, it is possible that the findings may have turned out to be different as it is likely that different countries and their people will have different attitudes towards and different perceptions regarding organizational innovation and HIT/EMR implementations. A third limitation of this study is that the survey design and data collection focused on EMR implementations only. EMR is, but one kind of HIT innovation. There are several other HIT innovations such as Mobile Health, (mHealth), Telemedicine, and Electronic Health (E-Health) which are not the focus of this study.

Research literature discusses multiple dimensions of organizational innovation including innovation leadership, organizational innovative culture, organizational learning, and knowledge management (Crossan \& Apaydin, 2010; Liao \& Wu, 2010; Yazhou \& Jian, 2013). Prior research studies have discussed the impact of one or more dimensions in particular IS contexts (Fay et al., 
2015; Roberts et al., 2016; Soto-Acosta et al., 2016). These dimensions were not incorporated in the current study considering the specific focus of this study. Further, adding many additional dimensions would have resulted in a substantial increase of the length of the questionnaire which would likely have increased the response burden and consequently reduced the response rate. Response burden is known to result in lower response rates, reduced completion, and reduced data quality (Diehr et al., 2005; Rolstad et al., 2011; Snyder et al., 2007). Future studies in this domain could consider incorporating the dimensions which were not considered by this study.

\section{CONCLUSION}

Successful HIT implementations could have multiple benefits for the healthcare industry including improved healthcare quality at a relatively lower cost, and efficiency and effectiveness in healthcare delivery. However, adoption of innovations in the healthcare industry has been much slower than in other industries. The inherent complexities involved in HIT innovation implementations have been cited as a major barrier to their successful implementation and adoption. Researchers have argued that the healthcare system is unique owing to its complexity and the involvement of people at all levels ranging from healthcare professionals to patients, and hence it is appropriate to study HIT implementations from a socio-technical perspective. All of the above, and additional aspects discussed in this article influenced the problem statement and hypotheses development this study.

This research study focused on uncovering the statistical association between organizational innovation capability based on past innovation implementation successes, and the ability of the organization to successfully implement HIT innovations such as EMR. Successful EMR implementations are expected to contribute to making healthcare operations efficient and effective leading to cost reduction and healthcare quality improvement, which is particularly important in the United States due to the ever-increasing cost of healthcare in the country, and also because there is an increasing focus on evidence-based medicine and on improving healthcare quality. As discussed in the article, this research study has important implications for both, academic researchers and practitioners. Future avenues of research can attempt to address limitations of this investigation. 


\section{REFERENCES}

About Cerner. (2020). https://www.cerner.com/about

Acar, A. Z., \& Acar, P. (2012). The effects of organizational culture and innovativeness on business performance in healthcare industry. Procedia: Social and Behavioral Sciences, 58, 683-692. doi:10.1016/j.sbspro.2012.09.1046

Adler, P. S., \& Shenbar, A. (1990). Adapting your technological base: The organizational challenge. Sloan Management Review, 32(1), 25-37.

Adler-Milstein, J., DesRoches, C. M., Kralovec, P., Foster, G., Worzala, C., Charles, D., Searcy, T., \& Jha, A. K. (2015). Electronic health record adoption in US hospitals: Progress continues, but challenges persist. Health Affairs, 34(12), 2174-2180. doi:10.1377/hlthaff.2015.0992 PMID:26561387

Adler-Milstein, J., Holmgren, A. J., Kralovec, P., Worzala, C., Searcy, T., \& Patel, V. (2017). Electronic health record adoption in US hospitals: The emergence of a digital "advanced use" divide. Journal of the American Medical Informatics Association: JAMIA, 24(6), 1142-1148. doi:10.1093/jamia/ocx080 PMID:29016973

Al-Hakim, L. A., \& Hassan, S. (2016). Core requirements of knowledge management implementation, innovation and organizational performance. Journal of Business Economics and Management, 17(1), 109-124. doi:10.38 46/16111699.2012.720597

Andargoli, A. E., Scheepers, H., Rajendran, D., \& Sohal, A. (2017). Health information systems evaluation frameworks: A systematic review. International Journal of Medical Informatics, 97, 195-209. doi:10.1016/j. ijmedinf.2016.10.008 PMID:27919378

Applebaum, S. H. (1997). Socio-technical systems theory: An intervention strategy for organizational development. Management Decision, 35(6), 452-463. doi:10.1108/00251749710173823

Ash, J. (1997). Organizational factors that influence information technology diffusion in academic health sciences centers. Journal of the American Medical Informatics Association: JAMIA, 4(2), 102-111. doi:10.1136/ jamia.1997.0040102 PMID:9067876

Ash, J. S., Sittig, D. F., Guappone, K. P., Dykstra, R. H., Richardson, J., Wright, A., Carpenter, J., McMullen, C., Shapiro, M., Bunce, A., \& Middleton, B. (2012). Recommended practices for computerized clinical decision support and knowledge management in community settings: A qualitative study. BMC Medical Informatics and Decision Making, 12(1), 6. doi:10.1186/1472-6947-12-6 PMID:22333210

Avgerou, C. (2003). New socio-technical perspectives of IS innovation in organizations. Academic Press.

Azar, G., \& Ciabuschi, F. (2017). Organizational innovation, technological innovation, and export performance: The effects of innovation radicalness and extensiveness. International Business Review, 26(2), 324-336. doi:10.1016/j.ibusrev.2016.09.002

Azaria, A., Ekblaw, A., Vieira, T., \& Lippman, A. (2016, August). Medrec: Using blockchain for medical data access and permission management. In 2016 2nd International Conference on Open and Big Data (OBD) (pp. 25-30). IEEE.

Barrett, A. K. (2018). Electronic health record (EHR) organizational change: Explaining resistance through profession, organizational experience, and EHR communication quality. Health Communication, 33(4), $496-506$. doi:10.1080/10410236.2016.1278506 PMID:28157382

Barrett, A. K., \& Stephens, K. K. (2017). Making electronic health records (ehrs) work: Informal talk and workarounds in healthcare organizations. Health Communication, 32(8), 1004-1013. doi:10.1080/10410236.2 016.1196422 PMID:27463257

Basole, R. C., \& Rouse, W. B. (2009). Enterprise readiness for IT innovation: A study of mobile computing in healthcare. ICIS 2009 Proceedings, 104.

Baxter, G., \& Sommerville, I. (2011). Socio-technical systems: From design methods to systems engineering. Interacting with Computers, 23(1), 4-17. doi:10.1016/j.intcom.2010.07.003

Baxter, G. J., \& Hester, A. J. (2014). Socio-technical systems theory as a diagnostic tool for examining underutilization of wiki technology. The Learning Organization. 
Beglaryan, M., Petrosyan, V., \& Bunker, E. (2017). Development of a tripolar model of technology acceptance: Hospital-based physicians' perspective on EHR. International Journal of Medical Informatics, 102, 50-61. doi:10.1016/j.jimedinf.2017.02.013 PMID:28495348

Bezboruah, K. C., Paulson, D., \& Smith, J. (2014). Management attitudes and technology adoption in long-term care facilities. Journal of Health Organization and Management. Advance online publication. doi:10.1108/ JHOM-11-2011-0118 PMID:25080649

Black, A. D., Car, J., Pagliari, C., Anandan, C., Cresswell, K., Bokun, T., McKinstry, B., Procter, R., Majeed, A., \& Sheikh, A. (2011). The impact of eHealth on the quality and safety of health care: A systematic overview. PLoS Medicine, 8(1), e1000387. doi:10.1371/journal.pmed.1000387 PMID:21267058

Bloomfield, R. A. Jr, Polo-Wood, F., Mandel, J. C., \& Mandl, K. D. (2017). Opening the Duke electronic health record to apps: Implementing SMART on FHIR. International Journal of Medical Informatics, 99, 1-10. doi:10.1016/j.jimedinf.2016.12.005 PMID:28118917

Bowman, S. (2013). Impact of electronic health record systems on informationintegrity: Quality and safety implications. Perspectives in Health Information Management, 10(Fall), 1c. PMID:24159271

Brooks, R., \& Grotz, C. (2010). Implementation of electronic medical records: How healthcare providers are managing the challenges of going digital. Journal of Business \& Economics Research, 8(6). Advance online publication. doi:10.19030/jber.v8i6.736

Byrd, W. M., \& Clayton, L. A. (2001). An American health dilemma: Race, medicine, and health care in the United States 1900-2000 (Vol. 2). Routledge. doi:10.4324/9780203950784

Cain, M., \& Mittman, R. (2002). Diffusion of innovation in health care. California Health Foundation.

Çakar, N. D., \& Ertürk, A. (2010). Comparing innovation capability of small and medium-sized enterprises: Examining the effects of organizational culture and empowerment. Journal of Small Business Management, 48(3), 325-359. doi:10.1111/j.1540-627X.2010.00297.x

Calantone, R. J., Cavusgil, S. T., \& Zhao, Y. (2002). Learning orientation, firm innovation capability, and firm performance. Industrial Marketing Management, 31(6), 515-524. doi:10.1016/S0019-8501(01)00203-6

Carayon, P., Wetterneck, T. B., Alyousef, B., Brown, R. L., Cartmill, R. S., McGuire, K., \& Weinger, M. B. et al. (2015). Impact of electronic health record technology on the work and workflow of physicians in the intensive care unit. International Journal of Medical Informatics, 84(8), 578-594. doi:10.1016/j.ijmedinf.2015.04.002 PMID:25910685

Castro, G. M., Buczkowski, L., \& Hafner, J. M. (2016). The contribution of sociotechnical factors to health information technology-related sentinel events. Joint Commission Journal on Quality and Patient Safety, 42(2), 70-AP3. doi:10.1016/S1553-7250(16)42008-8 PMID:26803035

Chan, K. S., Kharrazi, H., Parikh, M. A., \& Ford, E. W. (2016). Assessing electronic health record implementation challenges using item response theory. The American Journal of Managed Care, 22(12), e409-e415. PMID:27982669

Chaudhry, B., Wang, J., Wu, S., Maglione, M., Mojica, W., Roth, E., Morton, S. C., \& Shekelle, P. G. (2006). Systematic review: Impact of health information technology on quality, efficiency, and costs of medical care. Annals of Internal Medicine, 144(10), 742-752. doi:10.7326/0003-4819-144-10-200605160-00125 PMID: 16702590

Chaudoir, S. R., Dugan, A. G., \& Barr, C. H. (2013). Measuring factors affecting implementation of health innovations: A systematic review of structural, organizational, provider, patient, and innovation level measures. Implementation Science; IS, 8(1), 22. doi:10.1186/1748-5908-8-22 PMID:23414420

Chiasson, M. W., \& Davidson, E. (2004). Pushing the contextual envelope: Developing and diffusing IS theory for health information systems research. Information and Organization, 14(3), 155-188. doi:10.1016/j. infoandorg.2004.02.001

Christensen, C. M. (1999). Innovation and the general manager. Irwin Professional Pub. 
Colicchio, T. K., Cimino, J. J., \& Del Fiol, G. (2019). Unintended consequences of nationwide electronic health record adoption: Challenges and opportunities in the post-meaningful use era. Journal of Medical Internet Research, 21(6), e13313. doi:10.2196/13313 PMID:31162125

Costello, G. J., \& Donnellan, B. (2007). The diffusion of WOZ: Expanding the topology of IS innovations. Journal of Information Technology, 22(1), 79-86. doi:10.1057/palgrave.jit.2000085

Craig, S., \& Kodate, N. (2018). Understanding the state of health information in Ireland: A qualitative study using a socio-technical approach. International Journal of Medical Informatics, 114, 1-5. doi:10.1016/j. ijmedinf.2018.03.001 PMID:29673598

Crane, J., \& Crane, F. G. (2006). Preventing medication errors in hospitals through a systems approach and technological innovation: A prescription for 2010. Hospital Topics, 84(4), 3-8. doi:10.3200/HTPS.84.4.3-8 PMID: 17131715

Cranfield, S., Hendy, J., Reeves, B., Hutchings, A., Collin, S., \& Fulop, N. (2015). Investigating healthcare IT innovations: A "conceptual blending" approach. Journal of Health Organization and Management, 29(7), 1131-1148. doi:10.1108/JHOM-08-2015-0121 PMID:26556172

Cresswell, K., \& Sheikh, A. (2013). Organizational issues in the implementation and adoption of health information technology innovations: An interpretative review. International Journal of Medical Informatics, 82(5), e73-e86. doi:10.1016/j.jimedinf.2012.10.007 PMID:23146626

Cresswell, K., Sheikh, A., Franklin, B. D., Krasuska, M., Nguyen, H. T., Hinder, S., \& Potts, H. W. et al. (2020a). Theoretical and methodological considerations in evaluating large-scale health information technology change programs. BMC Health Services Research, 20(1), 1-6. doi:10.1186/s12913-020-05355-7 PMID:32460830

Cresswell, K., Williams, R., \& Sheikh, A. (2020b). Developing and Applying a Formative Evaluation Framework for Health Information Technology Implementations: Qualitative Investigation. Journal of Medical Internet Research, 22(6), e15068. doi:10.2196/15068 PMID:32519968

Cresswell, K. M., \& Sheikh, A. (2014). Undertaking sociotechnical evaluations of health information technologies. Journal of Innovation in Health Informatics, 21(2), 78-83. doi:10.14236/jhi.v21i2.54 PMID:24841408

Cresswell, K. M., Worth, A., \& Sheikh, A. (2012). Comparative case study investigating sociotechnical processes of change in the context of a national electronic health record implementation. Health Informatics Journal, 18(4), 251-270. doi:10.1177/1460458212445399 PMID:23257056

Cronbach, L. J. (1951). Coefficient alpha and the internal structure of tests. Psychometrika, 16(3), 297-334. doi:10.1007/BF02310555

Crossan, M. M., \& Apaydin, M. (2010). A multi-dimensional framework of organizational innovation: A systematic review of the literature. Journal of Management Studies, 47(6), 1154-1191. doi:10.1111/j.14676486.2009.00880.x

Damanpour, F. (1987). The adoption of technological, administrative, and ancillary innovations: Impact of organizational factors. Journal of Management, 13(4), 675-688. doi:10.1177/014920638701300408

Damanpour, F. (1991). Organizational innovation: A meta-analysis of effects of determinants and moderators. Academy of Management Journal, 34(3), 555-590.

Damanpour, F. (1996). Organizational complexity and innovation: Developing and testing multiple contingency models. Management Science, 42(5), 693-716. doi:10.1287/mnsc.42.5.693

Damanpour, F., \& Evan, W. M. (1984). Organizational innovation and performance: The problem of organizational lag. Administrative Science Quarterly, 29(3), 392-409. doi:10.2307/2393031

Dansky, K. H., Brannon, D., Shea, D. G., Vasey, J., \& Dirani, R. (1998). Profiles of hospital, physician, and home health service use by older persons in rural areas. The Gerontologist, 38(3), 320-330. doi:10.1093/ geront/38.3.320 PMID:9640852

Dansky, K. H., \& Dirani, R. (1998). The use of health care services by people with diabetes in rural areas. The Journal of Rural Health, 14(2), 129-137. doi:10.1111/j.1748-0361.1998.tb00614.x PMID:9715001 
Dansky, K. H., Thompson, D., \& Sanner, T. (2006). A framework for evaluating eHealth research. Evaluation and Program Planning, 29(4), 397-404. doi:10.1016/j.evalprogplan.2006.08.009 PMID:17950868

Darlington, R. B. (1990). Regression and linear models. McGraw-Hill.

De Jongh, P. J., De Jongh, E., Pienaar, M. P., Gordon-Grant, H., Oberholzer, M., \& Santana, L. (2015). The impact of pre-selected variance in action factor thresholds on the stability and predictive power of logistic regression models in credit scoring. ORiON, 31(1), 17-37. doi:10.5784/31-1-162

DeLone, W. H., \& McLean, E. R. (1992). Information systems success: The quest for the dependent variable. Information Systems Research, 3(1), 60-95. doi:10.1287/isre.3.1.60

Diehr, P., Chen, L., Patrick, D., Feng, Z., \& Yasui, Y. (2005). Reliability, effect size, and responsiveness of health status measures in the design of randomized and cluster-randomized trials. Contemporary Clinical Trials, 26(1), 45-58. doi:10.1016/j.cct.2004.11.014 PMID:15837452

Do Carmo-Caccia-Bava, M., Guimaraes, T., \& Harrington, S. J. (2006). Hospital organization culture, capacity to innovate and success in technology adoption. Journal of Health Organization and Management, 20(3), 194-217. doi:10.1108/14777260610662735 PMID:16869354

Dolezel, D., \& McLeod, A. (2019). Big Data Analytics in Healthcare: Investigating the Diffusion of Innovation. Perspectives in Health Information Management, 16(Summer). PMID:31423120

Dougherty, D., \& Hardy, C. (1996). Sustained product innovation in large, mature organizations: Overcoming innovation-to-organization problems. Academy of Management Journal, 39(5), 1120-1153.

Downs, G. W. Jr, \& Mohr, L. B. (1976). Conceptual issues in the study of innovation. Administrative Science Quarterly, 21(4), 700-714. doi:10.2307/2391725

Dutta, B., \& Hwang, H. G. (2020). The adoption of electronic medical record by physicians: A PRISMAcompliant systematic review. Medicine, 99(8), e19290. doi:10.1097/MD.0000000000019290 PMID:32080145

Emani, S., Peters, E., Desai, S., Karson, A. S., Lipsitz, S. R., LaRocca, R., \& Williams, D. H. et al. (2018). Perceptions of adopters versus non-adopters of a patient portal: An application of diffusion of innovation theory. BMJ Health \& Care Informatics, 25(3), 149-157. doi:10.14236/jhi.v25i3.991

Emani, S., Yamin, C. K., Peters, E., Karson, A. S., Lipsitz, S. R., Wald, J. S., Williams, D. H., \& Bates, D. W. (2012). Patient perceptions of a personal health record: A test of the diffusion of innovation model. Journal of Medical Internet Research, 14(6), e150. doi:10.2196/jmir.2278 PMID:23128775

Epic Software \& Services. (2020). https://www.epic.com/software

Fay, D., Shipton, H., West, M. A., \& Patterson, M. (2015). Teamwork and organizational innovation: The moderating role of the HRM context. Creativity and Innovation Management, 24(2), 261-277. doi:10.1111/ caim. 12100

Feeny, D. F., \& Willcocks, L. P. (1998). Core IS capabilities for exploiting information technology. Sloan Management Review, 39(3), 9-21.

Ferlie, E. B., \& Shortell, S. M. (2001). Improving the quality of health care in the United Kingdom and the United States: A framework for change. The Milbank Quarterly, 79(2), 281-315. doi:10.1111/1468-0009.00206 PMID:11439467

Fornell, C., \& Larcker, D. F. (1981). Structural equation models with unobservable variables and measurement error: Algebra and statistics. Academic Press.

Freund, R. J., Wilson, W. J., \& Sa, P. (2006). Regression Analysis. Statistical Modeling of a response variable (2nd ed.). Elsevier.

Gagnon, M. P., Desmartis, M., Labrecque, M., Car, J., Pagliari, C., Pluye, P., Frémont, P., Gagnon, J., Tremblay, N., \& Légaré, F. (2012). Systematic review of factors influencing the adoption of information and communication technologies by healthcare professionals. Journal of Medical Systems, 36(1), 241-277. doi:10.1007/s10916010-9473-4 PMID:20703721 
Gagnon, M. P., Talla, P. K., Simonyan, D., Godin, G., Labrecque, M., Ouimet, M., \& Rousseau, M. (2014). Electronic health record acceptance by physicians: Testing an integrated theoretical model. Journal of Biomedical Informatics, 48, 17-27. doi:10.1016/j.jbi.2013.10.010 PMID:24184678

Gewald, H., \& Gewald, C. (2020). Inhibitors of Physicians' Use of Mandatory Hospital Information Systems (HIS). In Data Analytics in Medicine: Concepts, Methodologies, Tools, and Applications (pp. 1720-1737). IGI Global.

Gonzalez-Zapatero, C., Gonzalez-Benito, J., \& Lannelongue, G. (2016). Antecedents of Functional Integration During New Product Development: The Purchasing-Marketing Link. Industrial Marketing Management, 52, 47-59. doi:10.1016/j.indmarman.2015.07.015

Gosling, A. S., Westbrook, J. I., \& Braithwaite, J. (2003). Clinical team functioning and IT innovation: A study of the diffusion of a point-of-care online evidence system. Journal of the American Medical Informatics Association: JAMIA, 10(3), 244-251. doi:10.1197/jamia.M1285 PMID:12626379

Greenhalgh, T., Potts, H. W. W., Wong, G., Bark, P., \& Swinglehurst, D. (2009). Tensions and paradoxes in electronic patient record research: A systematic literature review using the meta-narrative method. The Milbank Quarterly, 87(4), 729-788. doi:10.1111/j.1468-0009.2009.00578.x PMID:20021585

Greenhalgh, T., Robert, G., Macfarlane, F., Bate, P., \& Kyriakidou, O. (2004). Diffusion of innovations in service organizations: Systematic review and recommendations. The Milbank Quarterly, 82(4), 581-629. doi:10.1111/j.0887-378X.2004.00325.x PMID:15595944

Gregor, S., \& Hevner, A. R. (2015, May). The front end of innovation: perspectives on creativity, knowledge and design. In International Conference on Design Science Research in Information Systems (pp. 249-263). Springer. doi:10.1007/978-3-319-18714-3_16

Grover, V., Fiedler, K., \& Teng, J. (1997). Empirical evidence on Swanson's tri-core model of information systems innovation. Information Systems Research, 8(3), 273-287. doi:10.1287/isre.8.3.273

Guo, U., Chen, L., \& Mehta, P. H. (2017). Electronic health record innovations: Helping physicians-One less click at a time. The HIM Journal, 46(3), 140-144. doi:10.1177/1833358316689481 PMID:28671038

Hackler, D., \& Saxton, G. D. (2007). The strategic use of information technology by nonprofit organizations: Increasing capacity and untapped potential. Public Administration Review, 67(3), 474-487. doi:10.1111/j.15406210.2007.00730.x

Hair, J. E. Jr, Anderson, R. E., \& Tatham, R. L. (1995). Multivariate data analysis (5th ed.). Macmillan Publishing Company.

Hamamura, F. D., Withy, K., \& Hughes, K. (2017). Identifying barriers in the use of electronic health records in Hawaii. Hawai'i Journal of Medicine \& Public Health: a Journal of Asia Pacific Medicine \& Public Health, 76(3, Suppl 1), 28. PMID:28435756

Hameed, M. A., Counsell, S., \& Swift, S. (2012). A conceptual model for the process of IT innovation adoption in organizations. Journal of Engineering and Technology Management, 29(3), 358-390. doi:10.1016/j. jengtecman.2012.03.007

Hamel, G. (2006). The Why, What, and How of Management Innovation. Harvard Business Review, 84, 72$84+163$

Hillestad, R., Bigelow, J., Bower, A., Girosi, F., Meili, R., Scoville, R., \& Taylor, R. (2005). Can electronic medical record systems transform health care? Potential health benefits, savings, and costs. Health Affairs, 24(5), 1103-1117. doi:10.1377/hlthaff.24.5.1103 PMID:16162551

Holt, J. M., Cusatis, R., Asan, O., Williams, J., Nukuna, S., Flynn, K. E., \& Crotty, B. H. (2019, August). Incorporating patient-generated contextual data into care: Clinician perspectives using the Consolidated Framework for Implementation Science. In Healthcare (p. 100369). Elsevier.

Hong, K. K., \& Kim, Y. G. (2002). The critical success factors for ERP implementation: An organizational fit perspective. Information \& Management, 40(1), 25-40. doi:10.1016/S0378-7206(01)00134-3

Hoyle, R. H. (1995). Structural equation modeling: Concepts, issues, and applications. Sage (Atlanta, Ga.). 
Hsiao, J. L., Chang, H. C., \& Chen, R. F. (2011). A study of factors affecting acceptance of hospital information systems: A nursing perspective. The Journal of Nursing Research, 19(2), 150-160. doi:10.1097/ JNR.0b013e31821cbb25 PMID:21586992

Huber, P. J. (1967, June). The behavior of maximum likelihood estimates under nonstandard conditions. In Proceedings of the Fifth Berkeley Symposium on Mathematical Statistics and Probability (Vol. 1, No. 1, pp. 221-233). Academic Press.

Hunt, S. D., \& Morgan, R. M. (1996). The resource-advantage theory of competition: Dynamics, path dependencies, and evolutionary dimensions. Journal of Marketing, 60(4), 107-114. doi:10.1177/002224299606000410

Hurley, R. F., \& Hult, G. T. M. (1998). Innovation, market orientation, and organizational learning: An integration and empirical examination. Journal of Marketing, 62(3), 42-54. doi:10.1177/002224299806200303

Hurt, H., \& Teigen, W. C. (1977). The development of a measure of perceived organizational innovativeness. Annals of the International Communication Association, 1(1), 377-385. doi:10.1080/23808985.1977.11923693

Hurt, H. T., Joseph, K., \& Cook, C. D. (1977). Scales for the measurement of innovativeness. Human Communication Research, 4(1), 58-65. doi:10.1111/j.1468-2958.1977.tb00597.x

Jardim, S. V. B., \& Martins, A. C. (2016). An Overview and a Future Perspective in Health Information Systems in Portugal. In Encyclopedia of E-Health and Telemedicine (pp. 987-997). IGI Global. doi:10.4018/978-14666-9978-6.ch077

Jassawalla, A. R., \& Sashittal, H. C. (2002). Cultures that support product-innovation processes. The Academy of Management Perspectives, 16(3), 42-54. doi:10.5465/ame.2002.8540307

Jawhari, B., Keenan, L., Zakus, D., Ludwick, D., Isaac, A., Saleh, A., \& Hayward, R. (2016a). Barriers and facilitators to Electronic Medical Record (EMR) use in an urban slum. International Journal of Medical Informatics, 94, 246-254. doi:10.1016/j.ijmedinf.2016.07.015 PMID:27573333

Jawhari, B., Ludwick, D., Keenan, L., Zakus, D., \& Hayward, R. (2016b). Benefits and challenges of EMR implementations in low resource settings: A state-of-the-art review. BMC Medical Informatics and Decision Making, 16(1), 116. doi:10.1186/s12911-016-0354-8 PMID:27600269

Joshi, K. D., Chi, L., Datta, A., \& Han, S. (2010). Changing the competitive landscape: Continuous innovation through IT-enabled knowledge capabilities. Information Systems Research, 21(3), 472-495. doi:10.1287/ isre. 1100.0298

Ju, T. L., Li, C. Y., \& Lee, T. S. (2006). A contingency model for knowledge management capability and innovation. Industrial Management \& Data Systems, 106(6), 855-877. doi:10.1108/02635570610671524

Kanga, S. G., Muthee, V. M., Liku, N., Too, D., \& Puttkammer, N. (2016). People, Process and Technology: Strategies for Assuring Sustainable Implementation of EMRs at Public-Sector Health Facilities in Kenya. AMIA ... Annual Symposium Proceedings - AMIA Symposium. AMIA Symposium, 2016, 677. PMID:28269864

Kaplan, B., \& Harris-Salamone, K. D. (2009). Health IT Success and Failure: Recommendations from Literature and an AMIA Workshop. Journal of American Medical Informatics Association, 16(3), 291-299. doi:10.1197/ jamia.M2997

Katzan, I., Speck, M., Dopler, C., Urchek, J., Bielawski, K., Dunphy, C., \& Parchman, A. et al. (2011). The Knowledge Program: An innovative, comprehensive electronic data capture system and warehouse. AMIA ... Annual Symposium Proceedings - AMIA Symposium. AMIA Symposium, 2011, 683. PMID:22195124

Kharrazi, H., Gonzalez, C. P., Lowe, K. B., Huerta, T. R., \& Ford, E. W. (2018). Forecasting the maturation of electronic health record functions among US hospitals: Retrospective analysis and predictive model. Journal of Medical Internet Research, 20(8), e10458. doi:10.2196/10458 PMID:30087090

Khazanchi, S., Lewis, M. W., \& Boyer, K. K. (2007). Innovation-supportive culture: The impact of organizational values on process innovation. Journal of Operations Management, 25(4), 871-884. doi:10.1016/j.jom.2006.08.003

Kilsdonk, E., Peute, L. W., \& Jaspers, M. W. (2017). Factors influencing implementation success of guidelinebased clinical decision support systems: A systematic review and gaps analysis. International Journal of Medical Informatics, 98, 56-64. doi:10.1016/j.jjmedinf.2016.12.001 PMID:28034413 
Kim, J. S., \& Chung, G. H. (2017). Implementing innovations within organizations: A systematic review and research agenda. Innovation, 19(3), 372-399. doi:10.1080/14479338.2017.1335943

Klein, K. J., \& Knight, A. P. (2005). Innovation implementation: Overcoming the challenge. Current Directions in Psychological Science, 14(5), 243-246. doi:10.1111/j.0963-7214.2005.00373.x

Kogut, B., \& Zander, U. (1992). Knowledge of the firm, combinative capabilities, and the replication of technology. Organization Science, 3(3), 383-397. doi:10.1287/orsc.3.3.383

Krist, A. H. (2015). Electronic health record innovations for healthier patients and happier doctors. Am Board Family Med, 28(3).

Kruse, C. S., Mileski, M., Alaytsev, V., Carol, E., \& Williams, A. (2015). Adoption factors associated with electronic health record among long-term care facilities: A systematic review. BMJ Open, 5(1), e006615. doi:10.1136/bmjopen-2014-006615 PMID:25631311

Kutner, M. H., Nachtsheim, C. J., Neter, J., \& Li, W. (2005). Applied linear statistical models (5th ed.). McGrawHill.

Kwahk, K. Y., \& Ahn, H. (2010). Moderating effects of localization differences on ERP use: A socio-technical systems perspective. Computers in Human Behavior, 26(2), 186-198. doi:10.1016/j.chb.2009.10.006

Laird-Maddox, M., Mitchell, S. B., \& Hoffman, M. (2014). Integrating research data capture into the electronic health record workflow: Real-world experience to advance innovation. Perspectives in Health Information Management, 11(Fall). PMID:25593571

Lam, A. (2005). Organizational Innovation. In J. Fagerberg, D. C. Mowery, \& R. R. Nelson (Eds.), The Oxford Handbook of Innovation (pp. 115-147). Oxford University Press.

Larisch, L. M., Amer-Wåhlin, I., \& Hidefjäll, P. (2016). Understanding healthcare innovation systems: The Stockholm region case. Journal of Health Organization and Management, 30(8), 1221-1241. doi:10.1108/ JHOM-04-2016-0061 PMID:27834601

Laughlin, S. R. (1999). An ERP game plan. The Journal of Business Strategy, 20(1), 32-37. doi:10.1108/eb039981

Lawson, B., \& Samson, D. (2001). Developing Innovation Capability in Organizations: A Dynamic Capabilities Approach. International Journal of Innovation Management, 5(3), 377-400. doi:10.1142/S1363919601000427

Lee, B. S., Walker, J., Delbanco, T., \& Elmore, J. G. (2016). Transparent electronic health records and lagging laws. Annals of Internal Medicine, 165(3), 219. doi:10.7326/M15-2827 PMID:27214266

Lee, F. W. (2000). Adoption of electronic medical records as a technology innovation for ambulatory care at the Medical University of South Carolina. Topics in Health Information Management, 21(1), 1-20. PMID:11010366

Lee, L. S., \& Fiedler, K. D. (2011). The impact of location-aware systems in hospitals: A tri-core perspective. International Journal of Information Systems in the Service Sector, 3(2), 1-12. doi:10.4018/jisss.2011040101

Lee, S. M., Kim, K., Paulson, P., \& Park, H. (2008). Developing a socio-technical framework for business-IT alignment. Industrial Management \& Data Systems, 108(9), 1167-1181. doi:10.1108/02635570810914874

Leedy, P., \& Ormrod, J. E. (2015). Practical research: Planning and design. Pearson Publishing.

Leidner, D. E., Preston, D., \& Chen, D. (2010). An examination of the antecedents and consequences of organizational IT innovation in hospitals. The Journal of Strategic Information Systems, 19(3), 154-170. doi:10.1016/j.jsis.2010.07.002

Li, J., Talaei-Khoei, A., Seale, H., Ray, P., \& MacIntyre, C. R. (2013). Health care provider adoption of eHealth: Systematic literature review. Interactive Journal of Medical Research, 2(1), e7. doi:10.2196/ijmr.2468 PMID:23608679

Liao, S. H., \& Wu, C. C. (2010). System perspective of knowledge management, organizational learning, and organizational innovation. Expert Systems with Applications, 37(2), 1096-1103. doi:10.1016/j.eswa.2009.06.109 
Lin, C. P., Guirguis-Blake, J., Keppel, G. A., Dobie, S., Osborn, J., Cole, A. M., \& Baldwin, L. M. (2016). Using the diffusion of innovations theory to assess socio-technical factors in planning the implementation of an electronic health record alert across multiple primary care clinics. Journal of Innovation in Health Informatics, 23(1), 450. doi:10.14236/jhi.v23i1.157 PMID:27348488

Lin, T. T., Paragas, F., Goh, D., \& Bautista, J. R. (2016). Developing location-based mobile advertising in Singapore: A socio-technical perspective. Technological Forecasting and Social Change, 103, 334-349. doi:10.1016/j.techfore.2015.06.002

Liu, B., Luan, S., \& Li, D. (2014). It-Enabled Business Innovation: Does CIO Capability Matter? A Perspective from Institutional Entrepreneurship Theory. In PACIS (p. 10). Academic Press.

Liu, G., Shah, R., \& Schroeder, R. G. (2006). Linking work design to mass customization: A sociotechnical systems perspective. Decision Sciences, 37(4), 519-545. doi:10.1111/j.1540-5414.2006.00137.x

Lorenzi, N. M., Novak, L. L., Weiss, J. B., Gadd, C. S., \& Unertl, K. M. (2008). Crossing the implementation chasm: A proposal for bold action. Journal of the American Medical Informatics Association: JAMIA, 15(3), 290-296. doi:10.1197/jamia.M2583 PMID:18308985

Lorenzi, N. M., Smith, J. B., Conner, S. R., \& Campion, T. R., Jr. (2004, October). The Success Factor Profile for Clinical Computer Innovation. In Medinfo (pp. 1077-1080). Academic Press.

Luna-Reyes, L. F., Zhang, J., Ramón Gil-García, J., \& Cresswell, A. M. (2005). Information systems development as emergent socio-technical change: A practice approach. European Journal of Information Systems, 14(1), 93-105. doi:10.1057/palgrave.ejis.3000524

Lundblad, J. P. (2003). A review and critique of Rogers' diffusion of innovation theory as it applies to organizations. Organization Development Journal, 21(4), 50.

Lyytinen, K., \& Rose, G. M. (2003). Disruptive information system innovation: The case of internet computing. Information Systems Journal, 13(4), 301-330. doi:10.1046/j.1365-2575.2003.00155.x

MacVaugh, J., \& Schiavone, F. (2010). Limits to the diffusion of innovation. European Journal of Innovation Management, 13(2), 197-221. doi:10.1108/14601061011040258

Martikainen, S., Kaipio, J., \& Lääveri, T. (2020). End-user participation in health information systems (HIS) development: Physicians' and nurses' experiences. International Journal of Medical Informatics, 137, 104117. doi:10.1016/j.jijmedinf.2020.104117 PMID:32179254

Mason, R. L., Gunst, R. F., \& Hess, J. L. (1989). Statistical design and analysis of experiments: Applications to Engineering and Science (2nd ed.). Wiley.

Mir, M., Casadesús, M., \& Petnji, L. H. (2016). The impact of standardized innovation management systems on innovation capability and business performance: An empirical study. Journal of Engineering and Technology Management, 41, 26-44. doi:10.1016/j.jengtecman.2016.06.002

Mu, J., Thomas, E., Peng, G., \& Di Benedetto, A. (2017). Strategic Orientation and New Product Development Performance: The Role of Networking Capability and Networking Ability. Industrial Marketing Management, 64, 187-20. doi:10.1016/j.indmarman.2016.09.007

Najafi-Tavani, S., Sharifi, H., \& Najafi-Tavani, Z. (2016). Market orientation, marketing capability, and new product performance: The moderating role of absorptive capacity. Journal of Business Research, 69(11), 5059-5064. doi:10.1016/j.jbusres.2016.04.080

Narattharaksa, K., Speece, M., Newton, C., \& Bulyalert, D. (2016). Key success factors behind electronic medical record adoption in Thailand. Journal of Health Organization and Management, 30(6), 985-1008. doi:10.1108/ JHOM-10-2014-0180 PMID:27681029

Neumeier, M. (2013). Using Kotter's change management theory and innovation diffusion theory in implementing an electronic medical record. Canadian Journal of Nursing Informatics, 8(1), 1-8.

Newman, D. (2018). Epic Systems Modules EpicCare Ambulatory, Hyperspace, Epic OpTime, Cadence. https:// healthcareitskills.com/epic-systems-modules/

Nunnally, J. C., Bernstein, I. H., \& Berge, J. M. T. (1967). Psychometric Theory (Vol. 226). McGraw-Hill. 
Or, C., Tong, E., Tan, J., \& Chan, S. (2018). Exploring factors affecting voluntary adoption of electronic medical records among physicians and clinical assistants of small or solo private general practice clinics. Journal of Medical Systems, 42(7), 121. doi:10.1007/s10916-018-0971-0 PMID:29845400

Palabindala, V., Pamarthy, A., \& Jonnalagadda, N. R. (2016). Adoption of electronic health records and barriers. Journal of Community Hospital Internal Medicine Perspectives, 6(5), 32643. doi:10.3402/jchimp.v6.32643 PMID:27802857

Palvia, P., Jacks, T., \& Brown, W. (2015). Critical issues in EHR implementation: Provider and vendor perspectives. Communications of the Association for Information Systems, 36(1), 36. doi:10.17705/1CAIS.03636

Palvia, S. C., Sharma, R. S., \& Conrath, D. W. (2001). A socio-technical framework for quality assessment of computer information systems. Industrial Management \& Data Systems, 101(5), $237-251$. doi: $10.1108 / 02635570110394635$

Parks, R., Wigand, R. T., Othmani, M. B., Serhier, Z., \& Bouhaddou, O. (2019). Electronic health records implementation in Morocco: Challenges of silo efforts and recommendations for improvements. International Journal of Medical Informatics, 129, 430-437. doi:10.1016/j.ijmedinf.2019.05.026 PMID:31445288

Patil, M., Puri, L., \& Gonzalez, C. M. (2008). Productivity and cost implications of implementing electronic medical records into an ambulatory surgical subspecialty clinic. Urology, 71(2), 173-177. doi:10.1016/j. urology.2007.09.024 PMID:18308076

Pellizzoni, L., Silva, S. D. A., \& Falavigna, A. (2020). Multilanguage health record database focused on the active follow-up of patients and adaptable for patient-reported outcomes and clinical research design. International Journal of Medical Informatics, 135, 104065. doi:10.1016/j.ijmedinf.2019.104065 PMID:31927468

Peppard, J., Lambert, R., \& Edwards, C. (2000). Whose job is it anyway? Organizational information competencies for value creation. Information Systems Journal, 10(4), 291-322. doi:10.1046/j.1365-2575.2000.00089.x

Perez, G., Popadiuk, S., \& Cesar, A. M. R. V. C. (2017). Internal factors that favor the adoption of technological innovation defined by information systems: A study of the electronic health record. RAI Revista de Administração e Inovação, 14(1), 67-78. doi:10.1016/j.rai.2016.12.003

Porter, M. E. (2009). A strategy for health care reform-Toward a value-based system. The New England Journal of Medicine, 361(2), 109-112. doi:10.1056/NEJMp0904131 PMID:19494209

Putzer, G. J., \& Park, Y. (2012). Are physicians likely to adopt emerging mobile technologies? Attitudes and innovation factors affecting smartphone use in the Southeastern United States. Perspectives in Health Information Management/AHIMA, American Health Information Management Association, 9(Spring).

Raglan, G. B., Margolis, B., Paulus, R. A., \& Schulkin, J. (2014). Electronic health record adoption among obstetrician/gynecologists in the United States: Physician practices and satisfaction. Journal for Healthcare Quality. PMID:28481842

Ranganathan, C., \& Afnan, A. (2012). Effective Implementation of Electronic Medical Record Systems: Insights from a Longitudinal Case Study. AMCIS 2012 Proceedings, 69.

Raut, A., Yarbrough, C., Singh, V., Gauchan, B., Citrin, D., Verma, V., \& Schwarz, R. et al. (2017). Design and implementation of an affordable, public sector electronic medical record in rural Nepal. Journal of Innovation in Health Informatics, 24(2), 862. doi:10.14236/jhi.v24i2.862 PMID:28749321

Reardon, J. L. (2009). Perceptions of an organizing vision for electronic medical records by independent physician practices. International Journal of Healthcare Information Systems and Informatics, 4(3), 16-37. doi:10.4018/ jhisi.2009070102

Reisman, M. (2017). EHRs: The challenge of making electronic data usable and interoperable. $P \& T, 42(9)$, 572. PMID:28890644

Ries, E. (2011). The lean startup: How today's entrepreneurs use continuous innovation to create radically successful businesses. Currency.

Roberts, N., Campbell, D. E., \& Vijayasarathy, L. R. (2016). Using information systems to sense opportunities for innovation: Integrating post-adoptive use behaviors with the dynamic managerial capability perspective. Journal of Management Information Systems, 33(1), 45-69. doi:10.1080/07421222.2016.1172452 
Rogers, E. M., \& Shoemaker, F. F. (1971). Communication of Innovations; A Cross-Cultural Approach. Free Press.

Rolland, C., \& Prakash, N. (2001). Matching ERP system functionality to customer requirements. Requirements Engineering, 2001 - Proceedings of the Fifth IEEE International Symposium, 66-75.

Rolstad, S., Adler, J., \& Rydén, A. (2011). Response burden and questionnaire length: Is shorter better? A review and meta-analysis. Value in Health, 14(8), 1101-1108. doi:10.1016/j.jval.2011.06.003 PMID:22152180

Sackey, E., Tuuli, M., \& Dainty, A. (2015). Sociotechnical systems approach to BIM implementation in a multidisciplinary construction context. Journal of Management Engineering, 31(1), A4014005. doi:10.1061/ (ASCE)ME.1943-5479.0000303

Savory, C., \& Fortune, J. (2015). From translational research to open technology innovation systems. Journal of Health Organization and Management, 29(2), 200-220. doi:10.1108/JHOM-01-2013-0021 PMID:25800333

Seddon, P., \& Yip, S. K. (1992). An empirical evaluation of user information satisfaction (UIS) measures for use with general ledger accounting software. Journal of Information Systems, 6(1), 75-92.

Sharma, L., Chandrasekaran, A., Boyer, K. K., \& McDermott, C. M. (2016). The impact of health information technology bundles on hospital performance: An econometric study. Journal of Operations Management, 41(1), 25-41. doi:10.1016/j.jom.2015.10.001

Shekelle, P. G., Morton, S. C., \& Keeler, E. B. (2006). Costs and Benefits of Health Information Technology. Evidence Report/Technology Assessment No. 132 (Prepared by the Southern California Evidence-based Practice Center Under Contract No. 290=02=0003). AHRQ Publication No. 06-E006. Agency for Healthcare Research and Quality, Rockville, MD.

Singh, H., \& Sittig, D. F. (2020). A sociotechnical framework for safety-related electronic health record research reporting: The SAFER reporting framework. Annals of Internal Medicine, 172(11, Supplement), S92-S100. doi:10.7326/M19-0879 PMID:32479184

Sittig, D. F., \& Singh, H. (2015). A new socio-technical model for studying health information technology in complex adaptive healthcare systems. In Cognitive Informatics for Biomedicine (pp. 59-80). Springer. doi:10.1007/978-3-319-17272-9_4

Sligo, J., Gauld, R., Roberts, V., \& Villa, L. (2017). A literature review for large-scale health information system project planning, implementation and evaluation. International Journal of Medical Informatics, 97, 86-97. doi:10.1016/j.ijmedinf.2016.09.007 PMID:27919399

Snyder, C. F., Watson, M. E., Jackson, J. D., Cella, D., \& Halyard, M. Y. (2007). Patient-reported outcome instrument selection: Designing a measurement strategy. Value in Health, 10, S76-S85. doi:10.1111/j.15244733.2007.00270.x PMID:17995477

Soto-Acosta, P., Popa, S., \& Palacios-Marqués, D. (2016). E-business, organizational innovation and firm performance in manufacturing SMEs: An empirical study in Spain. Technological and Economic Development of Economy, 22(6), 885-904. doi:10.3846/20294913.2015.1074126

Stanberry, K. (2011). US and global efforts to expand the use of electronic health records. Records Management Journal, 21(3), 214-224. doi:10.1108/09565691111186885

Streiner, D. L. (2003). Starting at the beginning: An introduction to coefficient alpha and internal consistency. Journal of Personality Assessment, 80(1), 99-103. doi:10.1207/S15327752JPA8001_18 PMID:12584072

Stroetmann, K. A. (2014). Health System Efficiency and eHealth Interoperability-How Much Interoperability Do We Need? In New Perspectives in Information Systems and Technologies (Vol. 2, pp. 395-406). Springer. doi:10.1007/978-3-319-05948-8_38

Sumner, M. (2015). EMR implementation: Lessons learned from ERP. In Enterprise Systems. Strategic, Organizational, and Technological Dimensions. Springer International Publishing. doi:10.1007/978-3-31917587-4_2

Swanson, E. B. (1994). Information systems innovation among organizations. Management Science, 40(9), 1069-1092. doi:10.1287/mnsc.40.9.1069 
Swanson, E. B., \& Ramiller, N. C. (1997). The organizing vision in information systems innovation. Organization Science, 8(5), 458-474. doi:10.1287/orsc.8.5.458

Thakur, R., Hsu, S. H., \& Fontenot, G. (2012). Innovation in healthcare: Issues and future trends. Journal of Business Research, 65(4), 562-569. doi:10.1016/j.jbusres.2011.02.022

Therin, F. (2003). Organizational learning and innovation in high tech small firms. Proceedings of the 36th Hawaii International Conference on System Sciences (IEEE Computer Society). doi:10.1109/HICSS.2003.1174262

Trist, E. (1981). The evolution of socio-technical systems as a conceptual framework and as an action research program. In A. H. Van de Ven \& W. F. Joyce (Eds.), Perspectives on Organization Design and Behavior. Wiley.

Trzeciak, S., \& Rivers, E. P. (2003). Emergency department overcrowding in the United States: An emerging threat to patient safety and public health. Emergency Medicine Journal, 20(5), 402-405. doi:10.1136/emj.20.5.402 PMID:12954674

Tutty, M. A., Carlasare, L. E., Lloyd, S., \& Sinsky, C. A. (2019). The complex case of EHRs: Examining the factors impacting the EHR user experience. Journal of the American Medical Informatics Association: JAMIA, 26(7), 673-677. doi:10.1093/jamia/ocz021 PMID:30938754

UNESCO Institute for Statistics. (2005). Oslo Manual, The Measurement of Scientific and Technological Activities (3rd ed.). UNESCO.

Vishwanath, A., Singh, S. R., \& Winkelstein, P. (2010). The impact of electronic medical record systems on outpatient workflows: A longitudinal evaluation of its workflow effects. International Journal of Medical Informatics, 79(11), 778-791. doi:10.1016/j.ijmedinf.2010.09.006 PMID:20947415

Waarts, E., van Everdingen, Y. M., \& Van Hillegersberg, J. (2002). The dynamics of factors affecting the adoption of innovations. Journal of Product Innovation Management, 19(6), 412-423. doi:10.1111/1540-5885.1960412

Wager, K. A. (2008). Assessing physician and nurse satisfaction with an ambulatory care EMR: One facility's approach. International Journal of Healthcare Information Systems and Informatics, 3(1), 63-74. doi:10.4018/ jhisi.2008010104

Wallace, J. E., Friesen, S. P., White, D. E., Gilmour, J. G., \& Lemaire, J. B. (2010). The introduction of an electronic patient care information system and health care providers' job stress: A mixed-methods case study. International Journal of Healthcare Information Systems and Informatics, 5(4), 35-48. doi:10.4018/jhisi.2010100103

West, M. A. (1990). The Social Psychology of Innovation in Groups. In Innovation and Creativity at Work: Psychological and Organizational Strategies. Chichester, UK: Wiley.

Westbrook, J. I., Braithwaite, J., Georgiou, A., Ampt, A., Creswick, N., Coiera, E., \& Iedema, R. (2007). Multimethod evaluation of information and communication technologies in health in the context of wicked problems and sociotechnical theory. Journal of the American Medical Informatics Association: JAMIA, 14(6), 746-755. doi:10.1197/jamia.M2462 PMID:17712083

Westbrook, J. I., Braithwaite, J., Iedema, R., \& Coiera, E. W. (2004, January). Evaluating the impact of information communication technologies on complex organizational systems: a multi-disciplinary, multi-method framework. In Medinfo (pp. 1323-1327). Academic Press.

White, H. (1982). Maximum likelihood estimation of mis specified models. Econometrica, 1-25.

Winter, S., Berente, N., Howison, J., \& Butler, B. (2014). Beyond the organizational 'container': Conceptualizing 21st century sociotechnical work. Information and Organization, 24(4), 250-269. doi:10.1016/j. infoandorg.2014.10.003

Yazhou, W. A. N. G., \& Jian, L. I. N. (2013). An empirical research on knowledge management orientation and organizational performance: The mediating role of organizational innovation. African Journal of Business Management, 7(8), 604-612.

Yi, M. (2018). Major Issues in Adoption of Electronic Health Records. Journal of Digital Information Management, 16(4), 180. doi:10.6025/jdim/2018/16/4/180-191

Zaltman, G., Duncan, R., \& Holbeck, J. (1973). Innovativeness and Organizations. John Wiley and Sons. 
Zandieh, S. O., Yoon-Flannery, K., Kuperman, G. J., Langsam, D. J., Hyman, D., \& Kaushal, R. (2008). Challenges to EHR implementation in electronic-versus paper-based office practices. Journal of General Internal Medicine, 23(6), 755-761. doi:10.1007/s11606-008-0573-5 PMID:18369679

Rangarajan (Ray) Parthasarathy has received a Ph.D. in Computer and Information Science, MBA in Information Technology Management, and MS in Industrial Engineering. His research interests include cybersecurity, IS/IT implementation/adoption/use, health information technology, and innovation. He is a clinical assistant professor at the University of Illinois Urbana-Champaign.

Monica Garfield is a professor in the department of Computer Information Systems at Bentley University.

Anuradha Rangarajan has received a Ph.D. in Technology Management, and MS degrees in Computer Systems Engineering and Computer Science. Her research interests include health information technology, data analytics applications in IS/IT, cybersecurity, and knowledge management.

Justin L. Kern is an assistant professor in the department of educational psychology at University of Illinois Urbana-Champaign. 